\title{
Assessment of the Durability Performance of Fiber-Cement Sheets
}

\author{
M. Jamshidi ${ }^{1}$; H. R. Pakravan ${ }^{2}$; and F. Pacheco-Torgal ${ }^{3}$
}

\begin{abstract}
According to standards, the durability performance of fiber-cement sheets must be evaluated by comparing the modulus of rupture (MOR) before and after durability tests (freeze-thaw, soak-dry, and warm water) are completed. This paper investigated the MOR of two different fiber-cement sheets samples before and after durability tests as well as its ductility and toughness. Results showed no significant difference between the MOR of control specimens and that of the specimens submitted to durability tests except in the case of the freezing and thawing test where after 100 cycles, a 7-9\% decrease was observed. The differences between the MOR of the control specimens and that of the specimens submitted to durability tests were negligible and acceptable in accordance to the requirements of the standard. However, toughness and ductility decreased considerably in specimens of sample 1 by 25,35 , and $15 \%$, respectively, when exposed to soak-dry ( 25 and 50 cycles) and warm water conditions. In turn, the reduction in toughness and ductility for specimens of sample 2 exposed to soak-dry (50 cycles) and warm water conditions were of 40 and 7\%, respectively. The results of this investigation suggest that ductility and toughness should also be considered to assess the durability performance of fiber-cement sheets. DOI: 10.1061/(ASCE)MT.1943-5533.0000637. @ 2013 American Society of Civil Engineers.
\end{abstract}

CE Database subject headings: Cement; Sheets; Durability; Freeze and thaw.

Author keywords: Fiber-cement sheets; Durability; Freeze-thaw; Warm water; Soak-dry.

\section{Introduction}

The construction industry has a strong and positive effect on the economic growth of developing countries (Giang and Pheng 2011), being however responsible for an important part of waste production and also by playing a major part in carbon dioxide emissions. The industry needs to change its practices to more environmentally driven ones. In Iran, some studies have shown that the country needs to build 1.5 million housing units, which makes the construction industry one of its the most active industries. The high volume of housing and the need for rapid construction make the use of new technologies in construction mandatory. One material that has an effective role in the construction industry is fiber-cement sheets (Pacheco-Torgal and Jalali 2011). The presence of fibers in cement composites increases toughness, ductility, flexural capacity, and crack resistance. Increasing toughness and ductility enhances the energy adsorption capacity and the flexibility of the composite. The evaluation of these properties is important in the determination of fracture mechanisms and failure modes. Moreover, toughness and ductility are related to the debonding and pullout process of the reinforcing fibers bridging the cracks (Bentur and Mindess 2006; Hibbert and Hannant 1982).

\footnotetext{
${ }^{1}$ School of Chemical Engineering, Polymer Group, Iran Univ. of Science and Technology, Tehran 16846, Iran (corresponding author). E-mail: mjamshidi@iust.ac.ir

${ }^{2}$ Textile Engineering Dept., Amirkabir Univ. of Technology, Tehran 15875-4413, Iran.

${ }^{3}$ Civil Engineering Dept., Univ. of Minho, 4800-058 Guimarães, Portugal.

Note. This manuscript was submitted on May 11, 2011; approved on July 3, 2012; published online on August 29, 2012. Discussion period open until November 1, 2013; separate discussions must be submitted for individual papers. This paper is part of the Journal of Materials in Civil Engineering, Vol. 25, No. 6, June 1, 2013. (C) ASCE, ISSN 0899-1561/2013/ $6-819-823 / \$ 25.00$.
}

Fiber-cement sheets were produced for the first time in 1902 using a device for manufacturing thin sheets from cement slurry called the Hatschek machine. In this process, diluted slurry of cement, fibers, water, and silica are blended on a conveyor belt and dewatered. Then this layer is transferred to a mandrel and the process continues so that the desired thickness of the board can be achieved. Asbestos fibers were used extensively for reinforcement of cementitious materials until studies showed that the exposure to these fibers caused lung cancer. Although some authors (Swamy 1977) report the ancient use of asbestos, it was not until the nineteenth century that these fibers were explored and processed in industrial terms (Bernstein 2006). Due to cancer health risks (Azuma et al. 2009; Kumagai and Kurumatani 2009), Directive 83/477/EEC and amending Directives 91/382/EEC, 98/24/EC; 2003/18/EC and 2007/30/EC forbid the production of cementitious products based on these fibers (Pacheco-Torgal and Jalali 2011). The production of nonasbestos fiber-cement sheets in the U.S. construction industry began in the 1980s and the 1990s. In these years, this material had the fastest growing market share. At this point, asbestos usage was stopped in more than 50 countries and considerable research was initiated with the purpose of replacing it. As a result, the material is now being replaced by the use of synthetic fibers like polyvinyl alcohol (PVA) and polypropylene to produce fiber-cement products using the Hatscheck process. However, production of PVA and polypropylene needs phenol compounds as antioxidants, amines as ultraviolet stabilizers, and other compounds as flame retardants, all of which do not represent the path to more sustainable materials (Berge 2007). All of this created a large opportunity in the field of vegetable fiber cement-based materials. They are much cost-effective, as strong as synthetic fibers and, above all, are more environmentally friendly. Requirements of nonasbestos fibers in the Hatschek process include good mechanical properties, process ability, and long-term durability in the alkaline environment of the cement matrix, all of which cellulose fibers can fulfill (Kim et al. 1999). 
Several investigations have been performed on the evaluation of mechanical properties and durability of cellulose fiber-cement composites (Mohr et al. 2005; Morton et al. 2010). These studies have shown that the composite performance has been affected in durability tests due to degradation of the fibers' structure and/or disbonding at the interface of the fiber and cement matrix. The use of fiber-cement boards as facade or roofing materials cause them to be exposed to harsh atmospheric conditions (humidity, temperature, water, and frost). This phenomenon is present in Iran, being a country with a large variety of climatic conditions. EN 12467 [European Committee for Standardization (CEN) 2004] specifies the technical requirements for fiber-cement flat sheets, stating that the durability performance must be evaluated comparing the modulus of rupture (MOR) before and after the durability tests (freeze-thaw, soak-dry, and warm water). This paper presents the results of an investigation on the compliance of commercial fiber-cement sheets with the EN 12467 mechanical strength and durability requirements. In this purpose, two different sets of fiber-cement sheets (produced by different manufacturers) were selected. The test specimens were exposed to wet, warm water, soaking and drying, and freezing and thawing conditions. Then the flexural strength of the specimens was evaluated after conditioning. Due to the importance of ductility and toughness properties of the fiber-cement sheets on their performance under real loads, these were measured using the flexural strength-deflection curves.

\section{Materials and Methods}

\section{Fiber-Cement Boards}

Two types of fiber-cement boards were used in this research. Both were NT type and both make use of cellulose short fibers as the major reinforcing fiber. The samples were:

1. Fiber-cement board produced by Vista Company in China and that had a specific weight of $1,700 \mathrm{~kg} / \mathrm{m}^{3}$ and thickness of $8 \mathrm{~mm}$.

2. Fiber-cement board produced by Shera Company in Thailand that had a specific weight of $1,300 \mathrm{~kg} / \mathrm{m}^{3}$ and thickness of $8.6 \mathrm{~mm}$. Additionally, this sample was used only for validation of test results of sample 1. For this purpose, the board was only evaluated in warm water, 100 cycles of freezing and thawing, and 50 cycles of soaking and drying tests.

\section{Specimen Preparation}

Specimens with dimensions of $100 \times 250 \mathrm{~cm}$ were cut from five sampled fiber-cement sheets. Ten specimens (five pairs) in longitudinal $(L)$ and cross-sectional $(W)$ directions of the sheets were cut for each test.

\section{Test Procedure}

- Dry and wet conditioning: 10 specimens (five pairs) were placed, in a laboratory, at room temperature of $23 \pm 2^{\circ} \mathrm{C}$ and relative humidity of $40 \pm 5 \%$ for dry conditioning. Ten specimens (five pairs) were placed for $24 \mathrm{~h}$ in water with a temperature of $23 \pm 2{ }^{\circ} \mathrm{C}$ for wet conditioning. All specimens were tested for the three-point flexural strength test on the basis of EN 12467 (CEN 2004).

- Freeze and thaw test: 10 specimens (five pairs) were removed from water and placed in a freezing unit at a temperature of $-20 \pm 2^{\circ} \mathrm{C}$ for $2 \mathrm{~h}$. Then they were removed and transferred to water at ambient temperature $\left(23 \pm 2^{\circ} \mathrm{C}\right)$. Also, the specimens were exposed to freeze and thaw conditions for 25 and 100 cycles. Finally, the specimens were tested in accordance with the three-point flexural strength test.

- Soak and dry test: 10 specimens (five pairs) were removed from water and placed in an oven at a temperature of $60^{\circ} \mathrm{C}$ and humidity of $20 \%$ for $6 \mathrm{~h}$. Then they were removed and transferred to water at ambient temperature $\left(23 \pm 2^{\circ} \mathrm{C}\right)$. The specimens were finally tested trough the three-point flexural strength test.

- Warm water test: 10 specimens (five pairs) were removed from water and placed for 56 days in water at a temperature of $60^{\circ} \mathrm{C}$. Then they were also tested in the three-point flexural strength test.

\section{Results and Discussions}

\section{Flexural Strength}

- Dry and wet specimens: The flexural behavior of the dry- and wet-conditioned specimens was evaluated on the basis of EN 12467 (CEN 2004). Results of the flexural behavior of sample 1 are shown in Fig. 1. It is evident that the maximum flexural load borne by the specimens decreased considerably in wetconditioned specimens while, in turn, the deflection increased in these specimens in comparison with dry specimens. A similar trend was observed in sample 2, the results of which are shown in Fig. 2. Both specimens showed a decrease in the flexural strength and increased deflection after the wet conditioning.

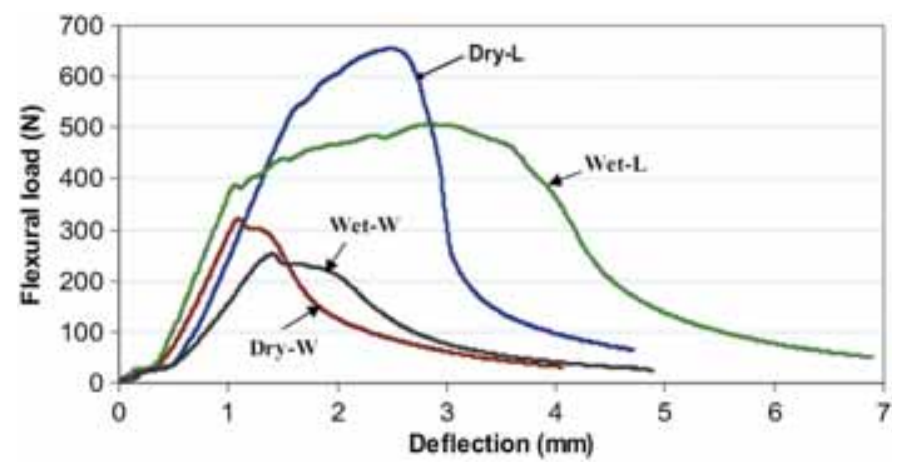

Fig. 1. Flexural behavior of dry- and wet-conditioned specimens of sample 1

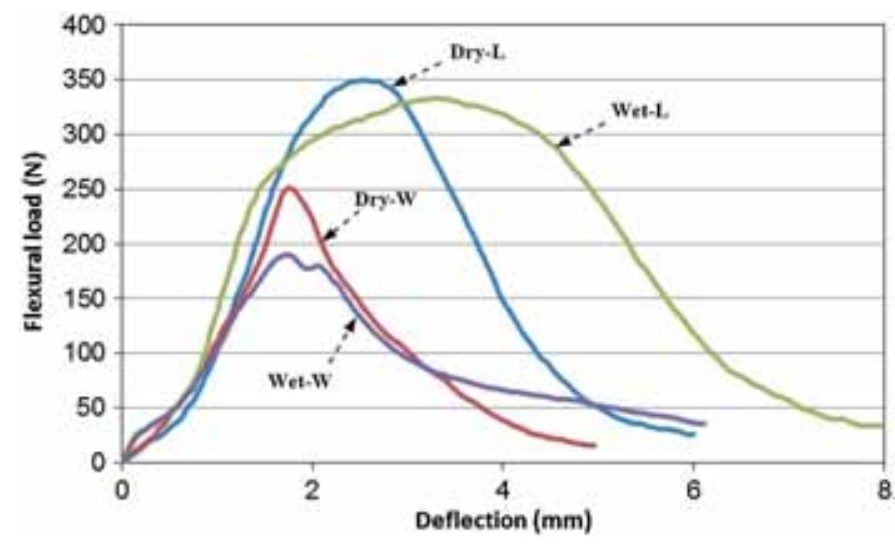

Fig. 2. Flexural behavior of dry- and wet-conditioned specimens of sample 2 
This should be attributed to the water absorption of the cement matrix, which decreased stiffness and increased ductility of the specimens.

- Freezing and thawing cycles: The flexural behavior of the specimens of sample 1, which were exposed to 25 and 100 cycles of freezing and thawing, are given in Fig. 3. It is evident that the freeze and thaw methodology has a minor effect on flexural behavior, especially after 25 cycles in both longitudinal and cross-sectional directions. Similar results were observed for specimens of sample 2 in turn exposed to 100 cycles of freezing and thawing. Those results are shown in Fig. 4.

- Warm water: The flexural behavior of the specimens of sample 1 when exposed to warm water is shown in Fig. 5. It is evident that warm water has a minor effect on the flexural behavior in both longitudinal and cross-sectional directions. A similar trend was observed in sample 2 (see Fig. 4).

- Soak and dry cycles: The flexural behavior of the specimens exposed to 25 and 50 cycles of soaking and drying are shown in Fig. 6. It can be observed that soaking and drying cycles do not have any effect in the maximum flexural load sustained by specimens, albeit the flexural behavior and the surface area under the load-deflection curves decreased by increasing exposure cycles. Fig. 7 shows the soaking and drying test results for sample 2. It is evident that the maximum flexural load sustained by these specimens slightly decreased in comparison with wet specimens. However, the surface area under the loaddeflection curves decreased in both longitudinal and crosssectional directions after exposure to 50 cycles of soaking and drying.

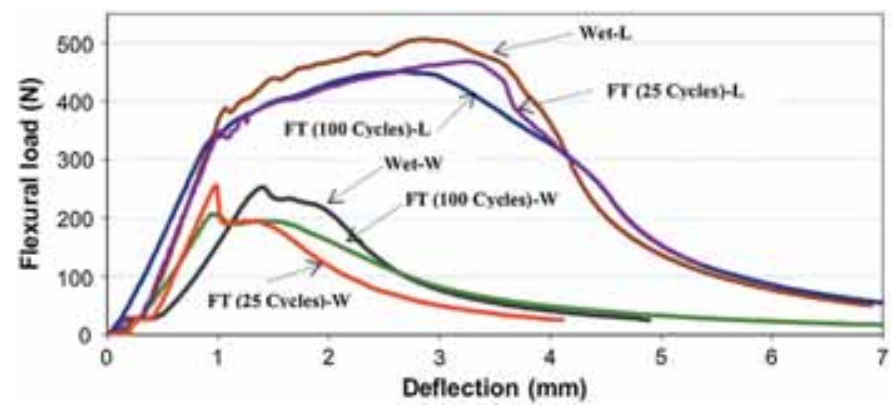

Fig. 3. Flexural behavior of specimens exposed to freeze and thaw cycles of sample 1

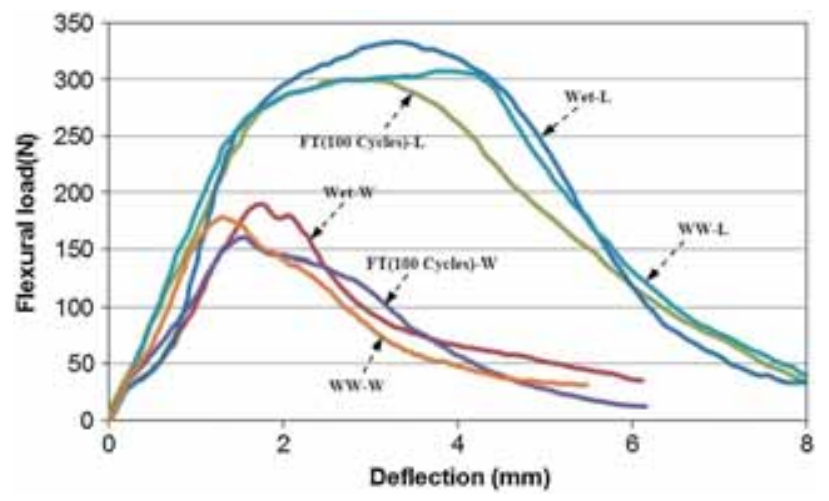

Fig. 4. Flexural behavior of specimens exposed to freeze and thaw cycles and warm water of sample 2

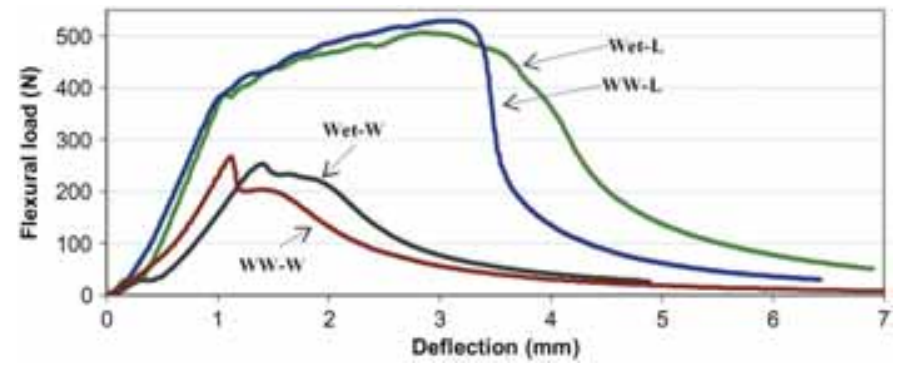

Fig. 5. Flexural behavior of specimens exposed to warm water of sample 1

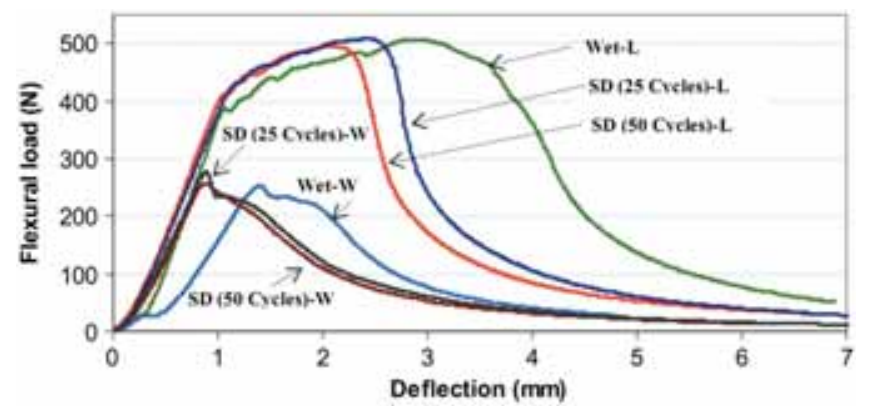

Fig. 6. Flexural behavior of specimens exposed to soak and dry cycles of sample 1

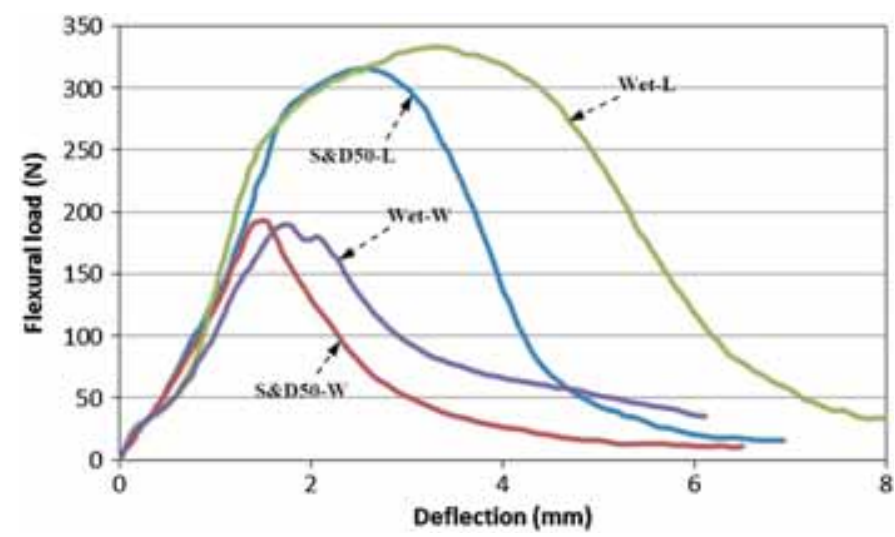

Fig. 7. Flexural behavior of specimens exposed to soak and dry cycles of sample 2

\section{Modulus of Rupture}

The modulus of rupture of all specimens was calculated as follows:

$$
\mathrm{MOR}=\frac{3 F L}{2 b h^{2}}
$$

where $F, L, b$, and $h$ are, respectively, the maximum load in load-deflection curve, the span length, the specimen width, and the thickness.

The MOR results of sample 1 are given in Fig. 8. The results show that the specimens exposed to water exhibit a decrease in the MOR in comparison with that of the dry specimens. The difference between the MOR of wet-conditioned specimens and the one of the specimens exposed to freeze and thaw, soak and dry, and warm water conditions was acceptable in accordance with the 


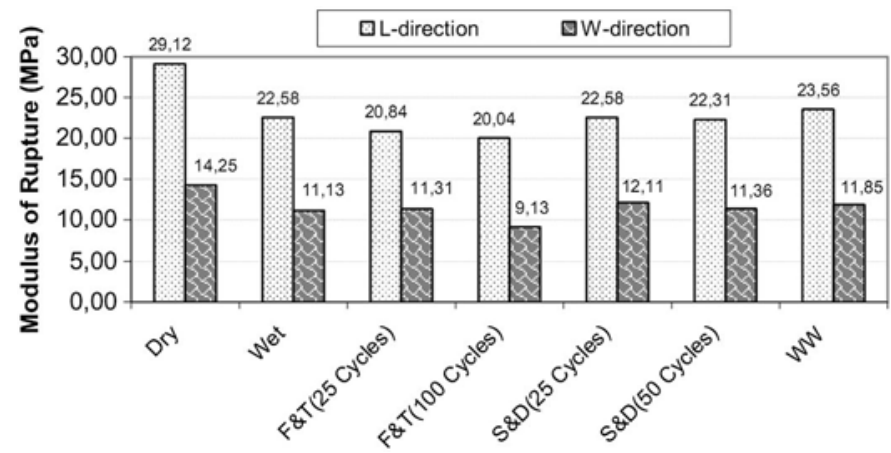

Fig. 8. Modulus of rupture of specimens in both directions of sample 1

Table 1. Minimum Flexural Strength for Various Classes according to EN12467 (CEN 2004)

\begin{tabular}{lc}
\hline Class & Minimum flexural strength (MPa) \\
\hline 1 & 4 \\
2 & 7 \\
3 & 10 \\
4 & 16 \\
5 & 22 \\
\hline
\end{tabular}

requirements of EN 12467 (CEN 2004). It is evident that only the specimens exposed to 25 and 100 cycles of freeze and thaw had a significant decrease in the MOR coefficient. On the basis of EN 12467 , this type of fiber-cement board meets class 5 of the durability classification-this standard suggests five classes for flexural strength as shown in Table 1.

The MOR results of sample 2 are given in Fig. 9. This type of fiber-cement board meets class 3 of the previously mentioned standard.

\section{Toughness and Ductility}

The toughness of the specimens was assessed by measuring the area under flexural load-deflection curves. Results are shown in Figs. 10 and 11. As can be seen, the water conditioning causes an increase in the toughness of the specimens. Also, in both samples it is clear that freezing and thawing cycles have a negligible effect on the toughness of the wet-conditioned specimens. For sample 1, soaking and drying (25 and 50) cycles and exposure to warm water caused a 25,35 , and $15 \%$ decrease in toughness,

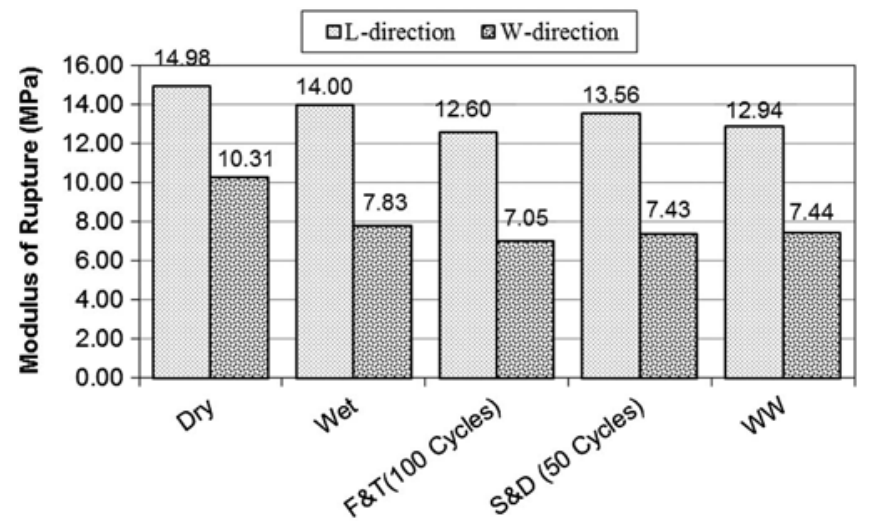

Fig. 9. Modulus of rupture of specimens in both directions of sample 2

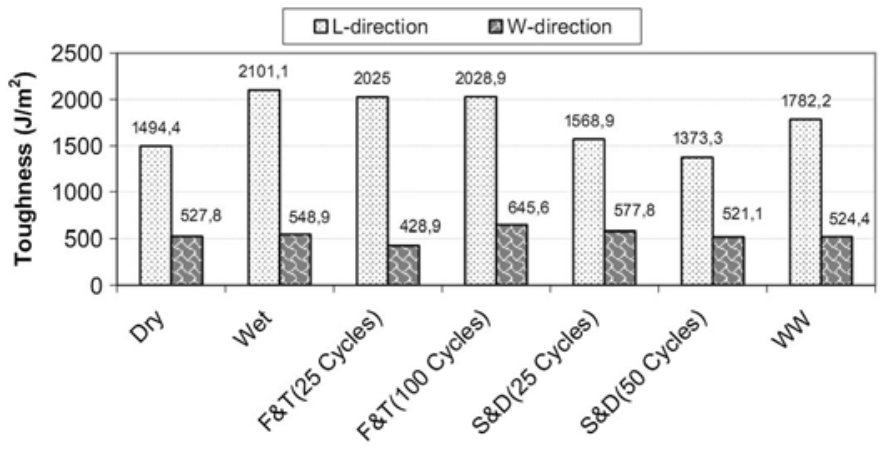

Fig. 10. Toughness of specimens in both directions of sample 1

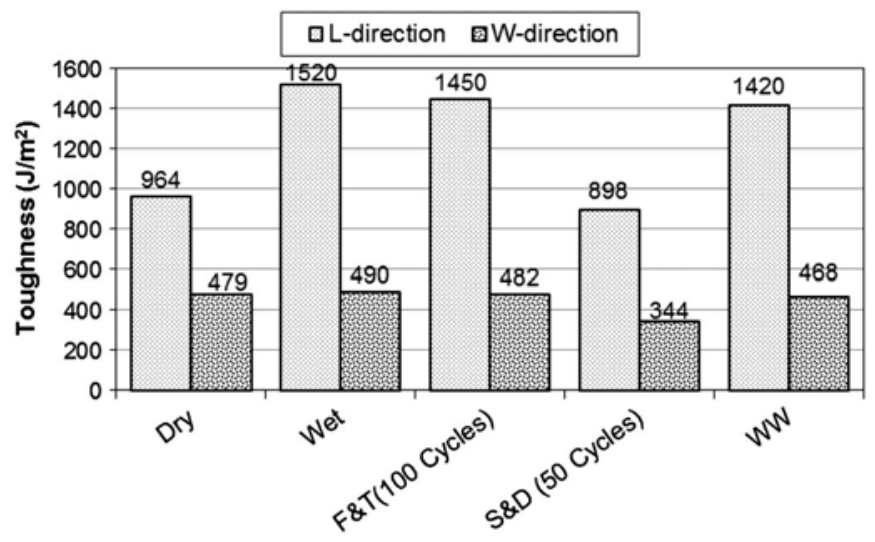

Fig. 11. Toughness of specimens in both directions of sample 2

respectively (see Fig. 10). For sample 2, exposed to soaking and drying (50 cycles) and warm water, toughness decreased 40 and $6 \%$, respectively.

The ductility of the specimens was determined by analyzing deflection of the specimens at a point that flexural load reaches $100 \mathrm{~N}$ (cracking mode) through flexural load-deflection curves. Results of the ductility of samples are shown in Figs. 12 and 13. Ductility of all the wet specimens increased in comparison to that of the dry specimens (e.g., toughness). It is therefore evident that ductility also shows the same trend as present in the toughness test. Additionally, there is a negligible difference between the ductility of wet-conditioned specimens to that of the specimens exposed to freeze and thaw cycles. The specimens of sample 1 that were exposed to soak and dry (25 and 50) cycles and warm water showed,

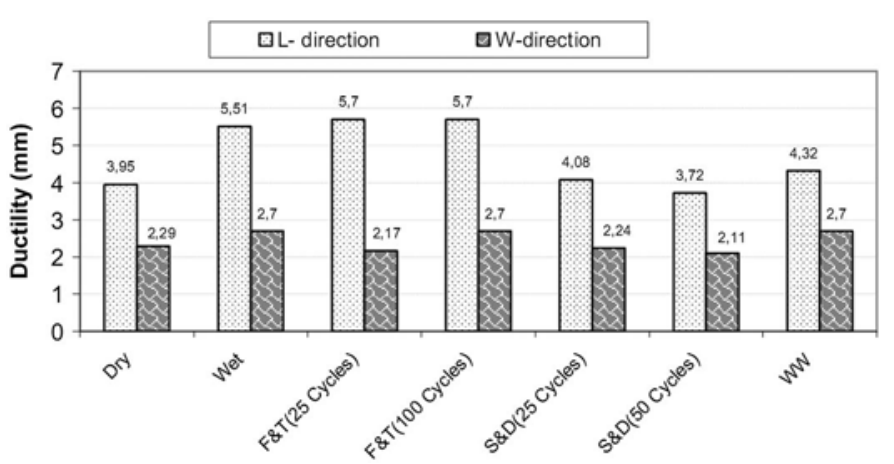

Fig. 12. Ductility of specimens in both directions of sample 1 


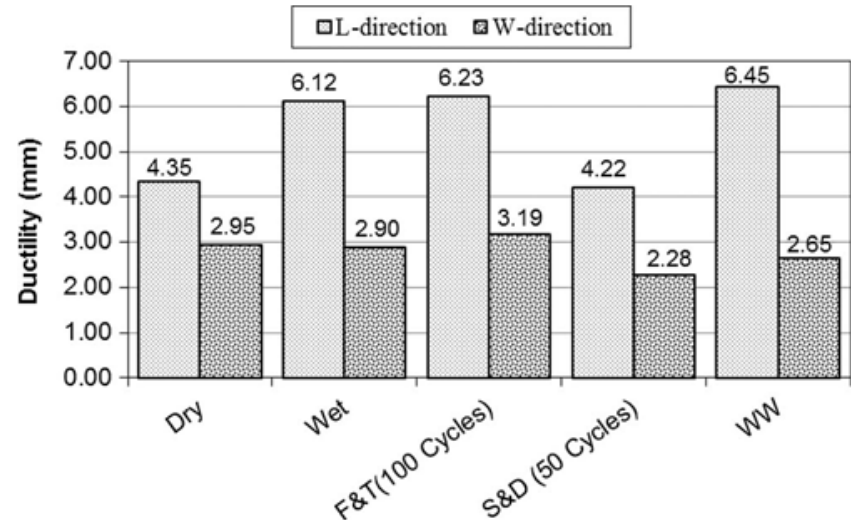

Fig. 13. Ductility of specimens in both directions of sample 2

respectively, a 26, 32, and $22 \%$ decrease in ductility results (see Fig. 13). Furthermore, it was found that there was not a significant difference between results of the specimens exposed to 25 and 100 cycles of freezing and thawing. Finally, for sample 2 the specimens exposed to soaking and drying (50 cycles) showed a 31\% decrease in ductility (see Fig. 13).

\section{Conclusions}

Durability of a fiber-cement board was studied in wet and dry conditioning, freeze and thaw, and soak and dry cycles and it was concluded that:

- Wet conditioning resulted in an increase in the toughness and ductility of fiber-cement boards and a decrease in the ability to resist flexure;

- Soaking, drying, and exposure to warm water tests resulted in the reduction of toughness by 25,35 , and $15 \%$, respectively;

- Soaking, drying, and exposure to warm water tests resulted in the reduction of ductility of the specimens by 26,32 , and $22 \%$, respectively;

- Soaking, drying, and warm water tests had no significant effects on flexural resistance and the MOR of the fiber-cement specimens;
- Freezing and thawing have minor effects on the flexural behavior in both longitudinal and cross-sectional directions of specimens especially after 25 cycles; and

- Ductility and toughness should be included in the assessment of the durability performance of fiber-cement sheets.

\section{References}

Azuma, K., Uchiyama, I., Chiba, Y., and Okumura, J. (2009). "Mesothelioma risk and environmental exposure to asbestos: Past and future trends in Japan." Int. J. Occup. Environ. Health, 15(2), 166-172.

Bentur, A., and Mindess, S. (2006). Fiber reinforced cementitious composites, 2nd Ed., Routledge, Taylor and Francis, New York.

Berge, B. (2007). The ecology of building materials, 2nd Ed., Architectural Press, Elsevier, Oxford, UK.

Bernstein, D. M. (2006). "Inhalation toxicology." Asbestos, H. Salem and S. Katz, eds., CRC Press, Boca Raton, FL, 647-667.

European Committee for Standardization (CEN). (2004). "Fibre-cement flat sheets-Product specification and test methods." EN 12467, Brussels, Belgium.

Giang, D., and Pheng, L. (2011). "Role of construction in economic development: Review of key concepts in the past 40 years." Habit. Int., 35(1), 118-125.

Hibbert, A. P., and Hannant, D. J. (1982). "Toughness of fiber cement composites." Composites, 13(2), 105-111.

Kim, P. J., Wu, H. C., Lin, Z., Li, V. C., deLhoneux, B., and Akers, S. A. S. (1999). "Micromechanics-based durability study of cellulose cement in flexture." Cem. Concr. Res., 29(2), 201-208.

Kumagai, S., and Kurumatani, N. (2009). "Asbestos fiber concentration in the area surrounding a former asbestos cement plant and excess mesothelioma deaths in residents." Am. J. Ind. Med., 52(10), 790-798.

Mohr, B. J., Nanko, H., and Kurtis, K. E. (2005). "Durability of kraft pulp fiber cement composites to wet/dry cycling." Cem. Concr. Compos., 27(4), 435-448.

Morton, J., Cooke, T., and Akers, S. (2010). "Performance of slash pine fibers in fiber cement products." Constr. Build. Mater., 24(2), $165-170$.

Pacheco-Torgal, F. P., and Jalali, S. (2011). "Cementitious building materials reinforced with vegetable fibers: A review." Constr. Build. Mater., 25(2), 575-581.

Swamy, R. N. (1977). "Fiber reinforcement of cement and concrete." Mater. Struct., 8(3), 235-254. 